\title{
Correction: Gulf of Mexico blue hole harbors high levels of novel microbial lineages
}

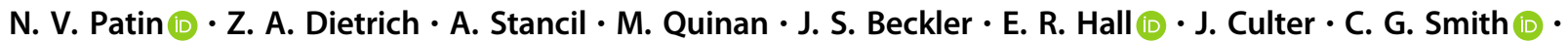 \\ M. Taillefert · F. J. Stewart
}

Published online: 25 May 2021

(C) The Author(s), under exclusive licence to International Society for Microbial Ecology 2021

Correction to: The ISME Journal

https://doi.org/10.1038/s41396-021-00917-x

The original version of this article unfortunately contained a mistake in the reference list and in-text citations:

All bins were assessed for quality using CheckM [121] and anvi'o (v6.1) [122]
Reference 122 is now listed as: Eren A. M., Kiefel E., Shaiber A., et al. 2021. Community-led, integrated, reproducible multi-omics with anvi'o. Nature Microbiology volume 6, pages 3-6. https://doi.org/10.1038/s41564-02000834-3. The subsequent references were re-numbered accordingly.

The original article has been corrected. 